\title{
How Different Types of Meditation Can Enhance Athletic Performance Depending on the Specific Sport Skills
}

\author{
Lorenza S. Colzato ${ }^{1,2,3}$ • Armin Kibele ${ }^{3}$
}

Received: 9 December 2016 / Accepted: 30 March 2017 / Published online: 11 April 2017

(C) The Author(s) 2017. This article is an open access publication

\begin{abstract}
Long-term engagement in mindfulness meditation has been found to be effective in achieving optimal athletic performance through decreasing the level of anxiety, ruminative thinking, and enhancing the experience of flow. Besides long-term training effects, the past years have seen an increasing interest in the impact of single bouts of meditation on cognition. In particular, focused attention meditation (FAM) and open monitoring meditation (OMM) instantly bias cognitive-control styles toward "more" (i.e., serial processing) versus "less" (i.e., parallel processing) top-down control, respectively. In this opinion article, we argue that the distinction between FAM and OMM is particularly effective when considering different types of sports. We speculate that FAM may enhance performance in closed-skills sports (i.e., archery, gymnastic), based on serial processing, in which the environmental is predictable and the response is "self-paced." In contrast, we consider OMM to promote performance in openskills sports (i.e., soccer, sailboarding), based on parallel processing, in which the environmental contingencies determine an "externally-paced" response. We conclude that successful meditation-based intervention on athletic performance
\end{abstract}

Lorenza S. Colzato

colzato@fsw.leidenuniv.nl

1 Cognitive Psychology Unit \& Leiden Institute for Brain and Cognition, Leiden University, Wassenaarseweg 52, 2333, AK Leiden, The Netherlands

2 Department of Cognitive Psychology, Institute of Cognitive Neuroscience, Faculty of Psychology, Ruhr University Bochum, Bochum, Germany

3 Institute for Sports and Sport Science, University of Kassel, Kassel, Germany requires a theoretically guided selection of the best-suited techniques specific to certain types of sports.

Keywords Mindfulness - Open-monitoring meditation · Focused-attention meditation · Closed-skills sports · Open-skills sports $\cdot$ Cognitive enhancement

\section{Introduction}

"Peak performance is meditation on motion" is a revealing quote by the Olympic champion diver Greg Louganis which nicely incorporates the crucial role of meditation in "making the mind quite" for many athletes. The inevitable pressure felt by athletes to enhance performance and to always be "king of the mountain" aggravates pre-competition anxiety and everyday anxiety (Terry and Slade 1995). Via (a) present-centered attention and (b) acceptance of experience, mindfulness meditation has been found to be effective in achieving optimal athletic performance through decreasing the level of anxiety, ruminative thinking, and enhancing the experience of flow (see Birrer et al. 2012 and Pineau et al. 2014, for a review). The key element of mindfulness is indeed the nonjudgmental focus of one's attention on the experience that takes place in the here and now (Kabat-Zinn 1994). Cottraux (2007) described mindfulness as "a mental state resulting from voluntarily focusing one's attention on one's present experience in its sensorial, mental, cognitive, and emotional aspects, in a non-judgmental way." Beyond the positive effect on wellbeing and immune system (Davidson et al. 2003), mindfulness has been found to increase the gray matter concentrations in brain regions involved in learning and memory processes (hippocampus), emotion regulation (posterior cingulate cortex), self-referential processing, and perspective taking (temporo-parietal junction) (Hölzel et al. 2011; Hölzel et al. 
2008). Furthermore, it has been found that reductions in perceived stress correlated positively with decreases in right basolateral amygdala gray matter density (Hölzel et al. 2010) after 8-week mindfulness-based stress reduction intervention. Related to it, in a seminal study, John et al. (2011) showed decrements in cortisol levels (stress hormone) in a group of elite shooters who underwent a training of mindfulness meditation ( 5 weeks), compared to a control group. From a recent survey, it seems that athletes perceive meditation as an important factor in enhancing sport performance, and the higher the level of sport proficiency, the more important meditation seems to be to cope with and to reduce anxiety levels (Kudlackova et al. 2013). Furthermore, several studies have shown that long-term mindfulness meditation practice enhances the experience of flow, which consists of the absence of negative thoughts and a feeling of enhanced physical and psychological functioning (Kee and Wang 2008; Bernier et al. 2009; Kaufman et al. 2009; Scott-Hamilton et al. 2016; Zhang et al. 2016). The experience of flow influences the performance of an athlete indirectly by playing an important role in keeping the athlete motivated over time (Jackson 2000).

Whereas in the studies mentioned above, meditation has been viewed as a long-term technique primarily intended for indirectly promoting sport performance via enhancing flow and anxiety reduction, the present opinion article presents the idea that short-term bouts of different prototypes of meditation might directly affect athletic performance by its enhancing cognitive effects when considering different types of sports.

\section{Focused Attention Meditation and Open Monitoring Meditation}

In their seminal work, Lutz et al. (2008) were the first to point out that two prototypes of meditation are usually investigated: focused attention meditation (FAM) and open monitoring meditation (OMM). Whereas FAM requires the voluntary focusing of attention on a chosen object, OMM involves an overt, but unreactive, monitoring of the content of experience from moment to moment (Lutz et al. 2008).

More recently, Lippelt et al. (2014) suggested that FAM and OMM are likely to exert different, to some degree even opposite effects on cognitive (control) processes. In line with the idea that different kinds of meditation affect human cognition in different ways, a recent meta-analysis concluded that different practices of meditation are indeed subserved by largely, if not entirely, disparate brain networks (Tomasino et al. 2013).

Usually, FAM is the beginning point for any novice meditator (Lutz et al. 2008; Vago and Silbersweig 2012). During FAM, the practitioner is required to focus attention on a chosen object or event, such as breathing or a piece of wood. To keep this focus, the practitioner has to constantly sustain the concentration on the chosen object so to prevent mind wandering (Tops et al. 2014). After practitioners get familiar with the FAM technique and can easily sustain their attentional focus on an object for a substantial amount of time, they often progress to OMM. In contrast to FAM, there is no object or event in the internal or external environment that the meditator has to focus on. The aim of OMM is rather to carry on the monitoring state, remaining attentive to any experience that might arise, without selecting, judging, or focusing on any particular object.

Recent studies have suggested that single bouts of FAM and OMM are sufficient to bias cognitive-control styles toward "more" versus "less" top-down control, respectively. As suggested elsewhere, FAM increases top-down control and thus strengthens top-down support for relevant information, while OMM weakens top-down control and thus reduces top-down support (Colzato et al. 2012; Colzato et al. 2015; Colzato et al. 2016). Figure 1 captures the emerging idea that FAM tends to strengthen the impact of the task goal and/or the competition between alternatives (cf., Hommel 2015) by supporting serial processing, whereas OMM tends to weaken the impact of the task goal and/or the competition between alternatives (cf., Hommel 2015) by supporting serial processing. In particular, evidence for the assumption that FAM strengthens top-down control by supporting parallel processing comes from several studies that show that FAM increases sustained attention (Carter et al. 2005; Brefczynski-Lewis et al. 2007). Neuroimaging evidence by Hasenkamp and colleagues (2012) suggests that FAM is associated with increased activity in the right dorsolateral prefrontal cortex, which has been associated with "the repetitive selection of relevant representations or recurrent direction of attention to

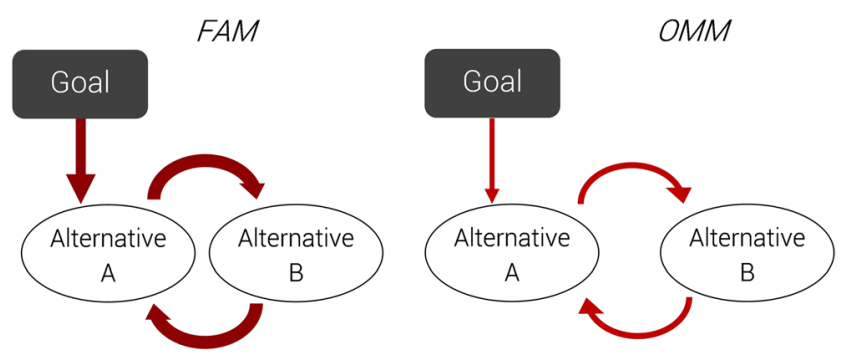

Fig. 1 Hypothetical impact of meditation-induced control states on cognition. Meditation is assumed to affect two parameters: the degree of competition between decision-making alternatives $(A$ and $B)$ and the degree to which this competition is biased by the current goal. Focusedattention meditation $(F A M)$ is characterized by strong competition and top-down bias. It is assumed to increase the impact of the task by supporting serial processing. In contrast, open-monitoring meditation $(O M M)$ is characterized by weak competition and top-down bias by supporting parallel processing. FAM might enhance cognitive performance in closed-skills sports (i.e., archery, gymnastic) which requires serial processing and in which the environment is predictable and the response is "self-paced." OMM might promote cognitive performance in open-skills sports (i.e., soccer, sailboarding) which requires parallel processing and in which the environmental contingencies determine an "externally paced" response 
those items" (D'Esposito 2007, p. 765). In line with these findings, Colzato et al. (2015) found that single bouts of FAM was successful in leading to a narrower distribution of attention over time.

In contrast, evidence for the hypothesis that OMM weakens top-down control by supporting parallel processing comes from several studies illustrating that OMM induces attention to be more flexible and continuously shifted to different objects (Chan and Woollacott 2007; Slagter et al. 2007; van Leeuwen et al. 2009; van Vugt and Slagter 2014). Furthermore, meditators showed improved flexible visual attention by identifying a greater number of alternative perspectives in multiple perspectives images (Hodgins and Adair 2010). Moreover, a study compared OMM and FAM meditators on a sustained attention task (Valentine and Sweet 1999): OMM meditators outperformed FAM meditators when the target stimulus was unexpected. This might indicate that the OMM meditators could be associated with a wider attentional scope.

In sum, because FAM and OMM support serial and parallel processing respectively, see Fig. 1, they show differential enhancing effect on attention: OMM improved flexible visual attention, whereas FAM supports sustained attention.

\section{Tailored Approach: Closed Skills vs. Open Skills Sports}

In the following section, we will argue that the distinction between FAM and OMM is particularly effective when considering different types of sports, such as closed-skills and open-skills sports.

Most meditation programs aimed to enhance athletic performance have a one-size-fits-all design and assume that athletes benefit from the intervention more or less the same way and to more or less the same degree irrespective of the skills type of the sport they are practicing. We propose that the efficiency of meditation-enhancing interventions will depend on the technical demands of the perpetrated sport. Accordingly, only enhancing programs that are tailored to skills, individual abilities, and needs are more likely to succeed.

Indeed, applying meditation effectively to sports necessitates an understanding of their technical demands. A broad range of sports are classified according to the skills and technical competencies they require (e.g., Magill and Anderson 2016). In closed-skills sports (i.e., archery, gymnastic), the action environment remains relatively stable and predictable over time. The object to be acted on does not change during the performance of the skill. In this kind of sports, performance is self-paced, that is, a responsive movement behavior is not needed. Time pressure is not interfering with performance. These sports typically are based on serial processing which requires sustained attention and where the sport performance takes place in a pre-determined sequence. Given that
FAM supports serial processing, we speculate that FAM might enhance performance in closed-skills sports. Interestingly, it has been recently shown that the stimulation of the dorsolateral prefrontal cortex, the same area impacted by FAM (Hasenkamp et al. 2012), was successful in promoting implicit motor learning in golf, a closed-skills sport (Zhu et al. 2015).

In contrast to closed-skills sports, in open-skills sports (e.g., soccer, sailboarding) the action environment is constantly changing and so movements have to be continuously adapted. Here, the performer must act according to the action of the object or the changing characteristics of the environment. Accordingly, in this kind of sports, performance is externally paced and the athlete needs to respond to external events/opponents in order to calibrate the next movements. Time pressure may perturb performance. These sports typically are based on parallel processing which requires flexible attention and the ability to perform multiple actions at the same time. Notably, it has been found that theta activity to be increased during meditation, primarily during OMM (for review, see Travis and Shear 2010). The same theta oscillation is involved in motor control. Recently, it was revealed that event-related synchronization in the theta band takes place in the contralateral motor area during the onset of fast ballistic movements (Ofori et al. 2015). Furthermore, theta oscillation was phase-locked with the onset of the movement and the theta power correlated with movement acceleration (Ofori et al. 2015). Given that OMM supports parallel processing, we propose that OMM might enhance performance in openskills sports.

In sum, because FAM and OMM support serial and parallel processing respectively, we expect them to be applied successfully in sports that mirror the kind of mental processes sustained by them.

\section{Relation to Previous Models}

Within the default-interventionist framework, Evans and Stanovich (2013) introduced the idea of two distinct types of processing: automatic vs. controlled. Type 1 processes are autonomous both started and finished in the presence of relevant triggering conditions and they do not involve working memory. On the other hand, type 2 processes are controlled and necessitate working memory because they entail hypothetical thinking and mental simulation (Evans and Stanovich 2013). The validity of default-interventionist framework applied to the field of sport has been recently presented by Furley et al. (2015). For example, the movement behavior of archers or shooters depends on type 1, but not type 2 processing. In contrast, executing open skills in game sports or combat sports could be prototypical examples for type 2 processing. We suggest that FAM might support type 1, whereas OMM might sustain type 2 processing in sport. 


\section{Conclusion}

We conclude that successful meditation-based intervention on athletic performance requires a theoretically guided selection of the best-suited exercises and techniques specific to certain types of sports.

Such theoretically guided selection will allow for the development of personalized, individually tailored meditation training programs. Not only will these meditation programs be more effective but they also will be much more motivating for athletes (as unnecessary failures due to sport-skills mismatches can be avoided) and more cost-efficient. This in turn will make the implementation of such interventions more likely even in times of sparse budgets. Our idea of personalized, individually tailored approach fits with the idiosyncratic framework of the multi-action plan model which proposes that there can be different strategies to achieve optimal performance outcomes as a function of the individual's psychophysical state at a particular moment (Bortoli et al. 2012; Bertollo et al. 2016).

Even though it seems plausible that different meditation types will be a future way to enhance mental performance in sport, it is important to acknowledge that extensive research is needed to verify our claims that FAM might enhance performance in closed-skills sports, whereas OMM might promote performance in open-skills sports.

Although more research is needed to fully understand the direct effects of different types of meditation on enhancing athletic performance, we propose that only taking into account the technical demands of the different kind of sports will allow us to design individualized meditation interventions.

Open Access This article is distributed under the terms of the Creative Commons Attribution 4.0 International License (http:// creativecommons.org/licenses/by/4.0/), which permits unrestricted use, distribution, and reproduction in any medium, provided you give appropriate credit to the original author(s) and the source, provide a link to the Creative Commons license, and indicate if changes were made.

\section{References}

Bernier, M., Thienot, E., Cordon, R., \& Fournier, J. F. (2009). Mindfulness and acceptance approaches in sport performance. Journal of Clinical Sport Psychology, 25(4), 320-333.

Bertollo, M., Di Fronso, S., Conforto, S., Schmid, M., Bortoli, L., Comani, S., \& Robazza, C. (2016). Proficient brain for optimal performance: the MAP model perspective. PeerJ, 4, e2082.

Birrer, D., Röthlin, P., \& Morgan, G. (2012). Mindfulness to enhance athletic performance: theoretical considerations and possible impact mechanisms. Mindfulness, 3(3), 235-246.

Bortoli, L., Bertollo, M., Hanin, Y., \& Robazza, C. (2012). Striving for excellence: a multi-action plan intervention model for shooters. Psychology of Sport and Exercise, 13(5), 693-701.

Brefczynski-Lewis, J. A., Lutz, A., Schaefer, H. S., Levinson, D. B., \& Davidson, R. J. (2007). Neural correlates of attentional expertise in long-term meditation practitioners. Proceedings of the National Academy of Sciences, 104(27), 11483-11488.

Carter, O. L., Presti, D. E., Callistemon, C., Ungerer, Y., Liu, G. B., \& Pettigrew, J. D. (2005). Meditation alters perceptual rivalry in Tibetan Buddhist monks. Current Biology, 15(11), R412-R413.

Chan, D., \& Woollacott, M. (2007). Effects of level of meditation experience on attentional focus: is the efficiency of executive or orientation networks improved? The Journal of Alternative and Complementary Medicine, 13, 651-658.

Colzato, L. S., Ozturk, A., \& Hommel, B. (2012). Meditate to create: the impact of focused-attention and open-monitoring training on convergent and divergent thinking. Frontiers in Psychology, 3(116), 1-5.

Colzato, L. S., Sellaro, R., Samara, I., Baas, M., \& Hommel, B. (2015). Meditation-induced states predict attentional control over time. Consciousness and Cognition, 37, 57-62.

Colzato, L. S., van der Wel, P., Sellaro, R., \& Hommel, B. (2016). A single bout of meditation biases cognitive control but not attentional focusing: evidence from the global-local task. Consciousness and Cognition, 39, 1-7.

Cottraux, J. (2007). Thérapie cognitive et emotions: La troisième vague [cognitive therapy and emotions: the third wave]. Paris: Elsevier Masson.

D'Esposito, M. (2007). From cognitive to neural models of working memory. Philosophical Transactions of the Royal Society B: Biological Sciences, 362, 761-772.

Davidson, R. J., Kabat-Zinn, J., Schumacher, J., Rosenkranz, M., Muller, D., Santorelli, S. F., et al. (2003). Alterations in brain and immune function produced by mindfulness meditation. Psychosomatic Medicine, 65(4), 564-570.

Evans, J. S. B. T., \& Stanovich, K. E. (2013). Dual-process theories of higher cognition: Advancing the debate. Perspectives on Psychological Science, 8, 223-241.

Furley, P., Schweizer, G., \& Bertrams, A. (2015). The two modes of an athlete: dual-process theories in the field of sport. International Review of Sport and Exercise Psychology, 8(1), 106-124.

Hasenkamp, W., Wilson-Mendenhall, C. D., Duncan, E., \& Barsalou, L. W. (2012). Mind wandering and attention during focused meditation: a fine-grained temporal analysis of fluctuating cognitive states. NeuroImage, 59(1), 750-760.

Hodgins, H. S., \& Adair, K. C. (2010). Attentional processes and meditation. Consciousness and Cognition, 19(4), 872-878.

Hölzel, B. K., Ott, U., Gard, T., Hempel, H., Weygandt, M., Morgen, K., \& Vaitl, D. (2008). Investigation of mindfulness meditation practitioners with voxel-based morphometry. Social Cognitive and Affective Neuroscience, 3(1), 55-61.

Hölzel, B. K., Carmody, J., Evans, K. C., Hoge, E. A., Dusek, J. A., Morgan, L., Pitman, R. K., \& Lazar, S. W. (2010). Stress reduction correlates with structural changes in the amygdala. Social Cognitive and Affective Neuroscience, 5(1), 11-17.

Hölzel, B. K., Carmody, J., Vangel, M., Congleton, C., Yerramsetti, S. M., Gard, T., \& Lazar, S. W. (2011). Mindfulness practice leads to increases in regional brain gray matter density. Psychiatry Research: Neuroimaging, 191(1), 36-43.

Hommel, B. (2015). Between persistence and flexibility: The Yin and Yang of action control. In: A.J. Elliot (ed.), Advances in Motivation Science, Vol. 2 (pp. 33-67). New York: Elsevier.

Jackson, S. A. (2000). Joy, fun, and flow state in sport. Emotions in Sport, $135-155$.

John, S., Verma, S. K., \& Khanna, G. L. (2011). The effect of mindfulness meditation on HPA-Axis in pre-competition stress in sports performance of elite shooters. National Journal of Integrated Research in Medicine, 2(3), 15-21.

Kabat-Zinn, J. (1994). Wherever you go, there are you: Mindfulness meditation in everyday life. New York: Hyperion.

Kaufman, K., Glass, C., \& Arnkoff, D. (2009). Evaluation of mindful sport performance enhancement (MSPE): a new approach to 
promote flow in athletes. Journal of Clinical Sports Psychology, 4(4), 334-356.

Kee, Y. H., \& Wang, C. J. (2008). Relationships between mindfulness, flow dispositions and mental skills adoption: a cluster analytic approach. Psychology of Sport and Exercise, 9(4), 393-411.

Kudlackova, K., Eccles, D. W., \& Dieffenbach, K. (2013). Use of relaxation skills in differentially skilled athletes. Psychology of Sport and Exercise, 14(4), 468-475.

van Leeuwen, S., Müller, N. G., \& Melloni, L. (2009). Age effects on attentional blink performance in meditation. Consciousness and Cognition, 18(3), 593-599.

Lippelt, D. P., Hommel, B., \& Colzato, L. S. (2014). Focused attention, open monitoring and loving kindness meditation: effects on attention, conflict monitoring and creativity. Frontiers in Psychology, 5, 1083.

Lutz, A., Slagter, H. A., Dunne, J. D., \& Davidson, R. J. (2008). Attention regulation and monitoring in meditation. Trends in Cognitive Sciences, 12(4), 163-169.

Magill, R. A., \& Anderson, D. I. (2016). Motor learning and control: concepts and applications. Boston: McGraw-Hill.

Ofori, E., Coombes, S. A., \& Vaillancourt, D. E. (2015). 3D cortical electrophysiology of ballistic upper limb movement in humans. NeuroImage, 115, 30-41.

Pineau, T. R., Glass, C. R., \& Kaufman, K. A. (2014). Mindfulness in sport performance. Oxford: Handbook of Mindfulness.

Scott-Hamilton, J., Schutte, N. S., \& Brown, R. F. (2016). Effects of a mindfulness intervention on sports-anxiety, pessimism, and flow in competitive cyclists. Applied Psychology: Health and Well-Being, 8(1), 85-103.

Slagter, H. A., Lutz, A., Greischar, L. L., Francis, A. D., Nieuwenhuis, S., Davis, J., \& Davidson, R. J. (2007). Mental training affects distribution of limited brain resources. PLoS Biology, 5(6), e138.

Terry, P. C., \& Slade, A. (1995). Discriminant effectiveness of psychological state measures in predicting performance outcome in karate competition. Perceptual and Motor Skills, 81(1), 275-286.
Tomasino, B., Fregona, S., Skrap, M., \& Fabbro, F. (2013). Meditationrelated activations are modulated by the practices needed to obtain it and by the expertise: an ALE meta-analysis study. Frontiers in Human Neuroscience, 6, 346.

Tops, M., Boksem, M. A., Quirin, M., IJzerman, H., \& Koole, S. L. (2014). Internally-directed cognition and mindfulness: An integrative perspective derived from reactive versus predictive control systems theory. Frontiers in Psychology, 5, 429.

Travis, F., \& Shear, J. (2010). Focused attention, open monitoring and automatic self-transcending: categories to organize meditations from Vedic, Buddhist and Chinese traditions. Consciousness and Cognition, 19(4), 1110-1118.

Vago, D. R., \& Silbersweig, D. A. (2012). Self-awareness, self-regulation, and self-transcendence (S-ART): a framework for understanding the neurobiological mechanisms of mindfulness. Frontiers in Human Neuroscience, 6(296), 1-30.

Valentine, E. R., \& Sweet, P. L. (1999). Meditation and attention: a comparison of the effects of concentrative and mindfulness meditation on sustained attention. Mental Health, Religion and Culture, 2(1), $59-70$.

van Vugt, M. K., \& Slagter, H. A. (2014). Control over experience? Magnitude of the attentional blink depends on meditative state. Consciousness and Cognition, 23, 32-39.

Zhang, C. Q., Si, G., Duan, Y., Lyu, Y., Keatley, D. A., \& Chan, D. K. (2016). The effects of mindfulness training on beginners' skill acquisition in dart throwing: a randomized controlled trial. Psychology of Sport and Exercise, 22, 279-285.

Zhu, F. F., Yeung, A. Y., Poolton, J. M., Lee, T. M., Leung, G. K., \& Masters, R. S. (2015). Cathodal transcranial direct current stimulation over left dorsolateral prefrontal cortex area promotes implicit motor learning in a golf putting task. Brain Stimulation, 8(4), 784-786. 